\title{
Rain-Wind-Induced Vibration of Cable Computed by Ansys
}

\author{
Lv Ling ${ }^{1, a}$, Zhao Lei ${ }^{2}$, Zhu Fang ${ }^{1}$ and Longfan Peng ${ }^{3}$ \\ ${ }^{1}$ XIANNING VOCATIONAL TECHNICAL COLLEGE, China \\ ${ }^{2} \mathrm{HuBei}$ Architectural Design Institute, China \\ ${ }^{3}$ Wuhan University of Technology, China
}

Keywords: Stay-cable; Rain-Wind-Induced Vibration; resistance measures.

\begin{abstract}
Stay cable is one of the main components of cable stayed bridge to bear loads. Due to its large flexibility, small quality and small damping, various of harmful vibrations could happen easily under the external excitations. Rain-wind-induced vibration is the strongest form of vibrations. Under the joint action of wind and rain, big vibration will take place. The vibration is relatively complex because the vibration belongs to three-phase coupling vibration. According to the existing water balance equation of rain-wind-induced vibration numerical analysis, the vibration of cable in different wind speed, wind directions and different waterway directions are respectively analyzed, the results show that the rain-wind-induced vibration of cable is greatly influenced by wind directions, and waterway directions has a very significant impact as well.
\end{abstract}

\section{Introduction}

With the increasing span of cable stayed bridge, the large cables are used widely nowadays. Because of the features that the cable is light, flexible, low damping and so on, the vibrations are easily occurred under the effects of wind, earthquake and vehicle load. The vibrations can make the cables become invalid, and even anyone is invalid can lead to integral instability and damage ${ }^{[1]}$.

At present, the main types of vibrations of cables are rain-wind-induced vibration, vortex-induced vibration, drafting aeroelasticity, cable internal resonance, chattering and parameter vibration etc which are accepted by the domestic and overseas scholars. Among the vibration types, the rain-windinduced vibration is the most intense type. So the rain-wind-induced vibration is also the hot field that many scholars are studying on. And some researches and methods about the resistance measures are carried out.

In this paper, rain-wind-induced vibration is analyzed in three factors: waterway directions, density of rain and wind, and wind directions.

a Corresponding author : zhaoleies@163.com 


\section{Rain-Wind-Induced Vibration of Cable}

Rain-wind-induced vibration means that the cables in a certain stance course a large amplitude vibration under the situations that the wind is in a certain speed and the vibration is caused by the joint action of wind and rain. And this type of vibration is the most intense as far as we know.

\subsection{Mechanism of Rain-Wind-Induced Vibration}

When the rain-wind-induced vibration happens, there is a stable waterway in the upper surface of cable. And this waterway could do the circular motion on the surface of cable with the frequency which is as same as the cable vertical movement ${ }^{[2]-[4]}$.

Cable and waterway motion diagrams are as shown in figure 1, which $U$ stands for wind speed, $y$ stands for cable amplitude, $\beta 0$ stands for waterway direction, $\gamma$ stands for the relatively instantaneous angel for $\beta$ 0.At time $t$, the cable speed is $y$, instantaneous wind speed is Urel, and it has the equation:

$$
U_{r e l}=\sqrt{U^{2}+\dot{y}^{2}}
$$

The angle a between Urel and $U$ is:

$$
\alpha=\arctan \frac{\dot{y}}{U}
$$
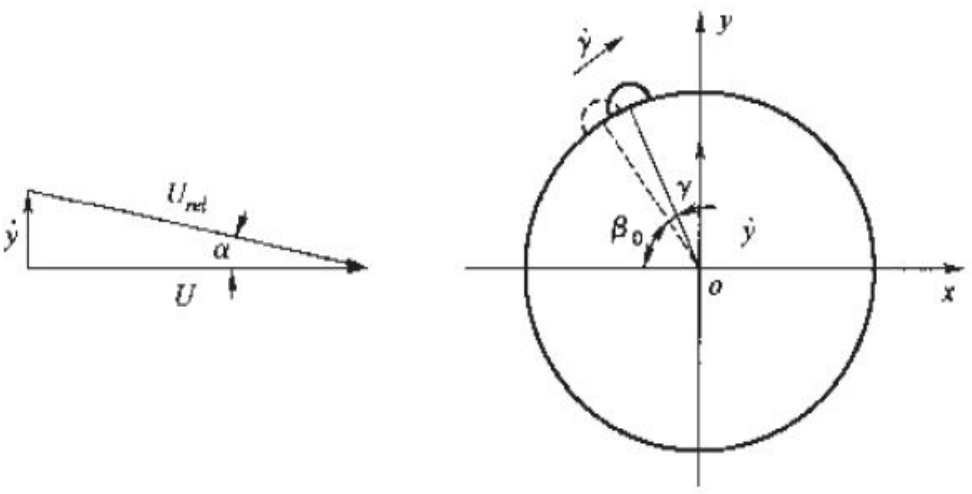

\section{Figure 1. Action of Cable and Waterway}

the kinds of load on the cable are easily obtained. Such as restoring force Ky, damping force $\mathrm{C}^{\dot{y}}$, inertia force $\mathrm{M}^{\ddot{y}}$. Besides, tangential and normal forces respectively are F1 and F2, resistance and lift forces respectively are FD and FL. Similarly also may obtained the loads of waterway. Waterway is under the load of gravity mg, the load F1 and F2 from cable, and so on.

According to the analysis above, the equations about motion of cable and waterway are as follows:

$$
\begin{aligned}
& M \dot{y}+C \dot{y}+K y+F_{2} \sin \left(\beta_{0}+\gamma\right)-F_{1} \cos \left(\beta_{0}+\gamma\right)+F_{D}(\theta) \sin \alpha-F_{L}(\theta) \cos \alpha=0 \\
& m(\ddot{y}+g) \cos \left(\beta_{0}+\gamma\right)-P^{\tau}+m R \ddot{\gamma}+F_{1}=0 \\
& m(\ddot{y}+g) \cos \left(\beta_{0}+\gamma\right)+P^{\tau}-m R \ddot{\gamma}-F_{1}=0
\end{aligned}
$$

As $\mathrm{M}$ is much larger than $\mathrm{m}$, the equations above can be written in such form:

$$
\ddot{y}+2 \omega \zeta y+\omega^{2} y-\delta\left[R \dot{\gamma}^{2} \sin \left(\beta_{0}+\gamma\right)-g \sin ^{2}\left(\beta_{0}+\gamma\right)\right]=\frac{F_{y}}{M}
$$




$$
\ddot{\gamma}+\frac{1}{R}(\ddot{y}+g) \cos \left(\beta_{0}+\gamma\right)=\frac{P^{\tau}}{m R}
$$

In this formula, $\omega=\sqrt{K / M}$ stands for cable frequence, $\zeta$ stands for cable damping ratio, $\delta=m / M$ stands for mass ratio of waterway and cable. So, in y axis, resultant force $F_{y}(\theta)$ combined FD with FL is equaled to:

$$
F_{y}(\theta)=\rho U^{2} C_{y}(\theta) / 2=F_{L}(\theta) \cos \alpha-F_{D}(\theta) \sin \alpha
$$

Based on the characteristics, when the waterway in the angle $\theta$, FD and FL are:

$$
F_{D}=\frac{1}{2} \rho U_{r e l}^{2} C_{D}(\theta) ; F_{L}=\frac{1}{2} \rho U_{r e l}^{2} C_{l}(\theta)
$$

Combined the two formula above together, $F_{y}(\theta)$ changes to the under form:

$$
F_{y}(\theta)=\rho U^{2} R\left[-C_{D}(\theta) \tan \alpha+C_{L}(\theta)\right] \frac{1}{\cos \alpha}
$$

In the formula, $\rho$ stands for the density of rain and wind, $C_{D}(\theta)$ and $C_{L}(\theta)$ respectively stands for resistance coefficient and lift coefficient when cable with waterway in the angle $\theta$.

\subsection{Numerical analysis of Rain-Wind-Induced Vibration}

According to the mechanism stated above, the influence of rain-wind-induced vibration may focus on waterway direction, the density of rain and wind, and wind direction.

Firstly, consider the influence of waterway direction with wind speed. the regular amplitudes of vibration are shown in figure 2 .

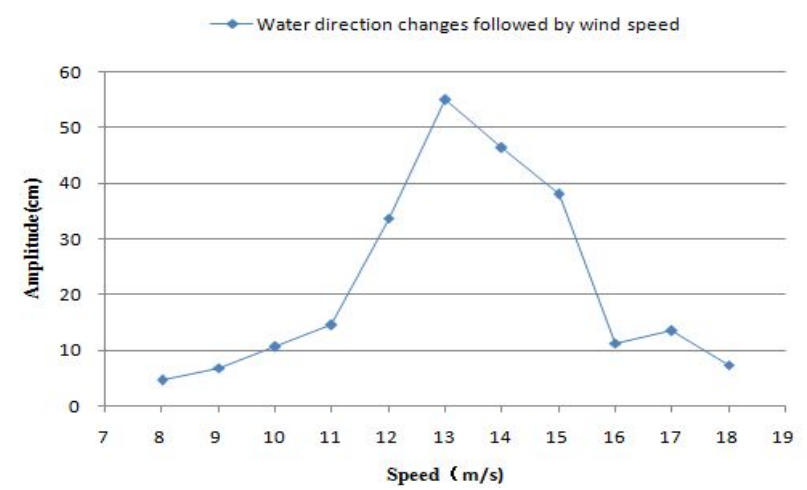

Figure 2. The Amplitude of Waterway Direction with Wind Speed

As shown in the figure, when wind speed in the area of $11 \mathrm{~m} / \mathrm{s} \sim 16 \mathrm{~m} / \mathrm{s}$, the amplitude of vibration is much larger than any other area. Besides, the amplitude reaches the highest at $54.91 \mathrm{~cm}$ when speed is $13 \mathrm{~m} / \mathrm{s}$, while the lowest at $7.36 \mathrm{~cm}$ when $18 \mathrm{~m} / \mathrm{s}$. In conclusion, the obvious vibration only occurs in a special wind speed area.

Secondly, the density of rain and wind has an obvious effect on the vibration. Take $1.2261 \mathrm{~kg} / \mathrm{m} 3,2.0 \mathrm{~kg} / \mathrm{m} 3$ and $3.5 \mathrm{~kg} / \mathrm{m} 3$ as three respective densities, the following figure demonstrates the amplitudes increase along with the density increases. At the same speed of $13 \mathrm{~m} / \mathrm{s}$, the amplitudes respectively are $5.58 \mathrm{~cm}, 54.91 \mathrm{~cm}$ and $99.15 \mathrm{~cm}$.To sum up, as the mixed density increased, or as the rainfall growed, the vibration becomes more evident. 


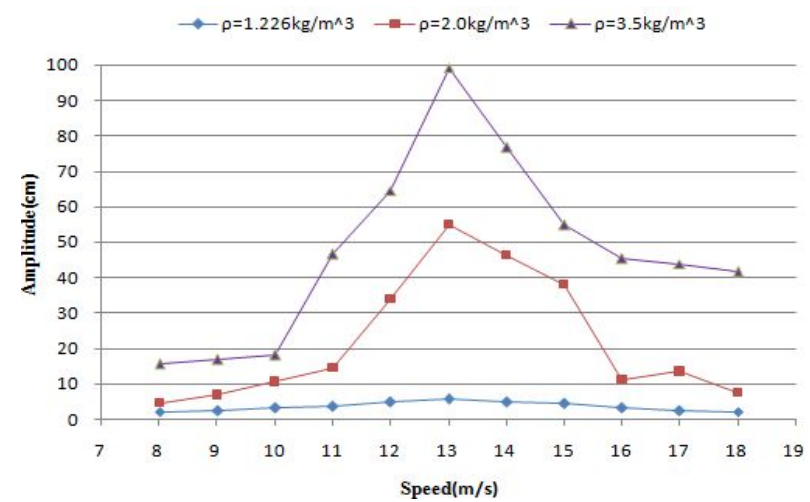

Figure 3. The Amplitude of Mixed Density with Wind Speed

Lastly, taking wind direction into consideration. As stated above, only when there is waterway on the cable, in other words, when $\beta>0^{\circ}$, the vibration can be observed. In this research paper, $30^{\circ}, 40^{\circ}$ and $50^{\circ}$ are considered to analyse the amplitudes of the vibration.

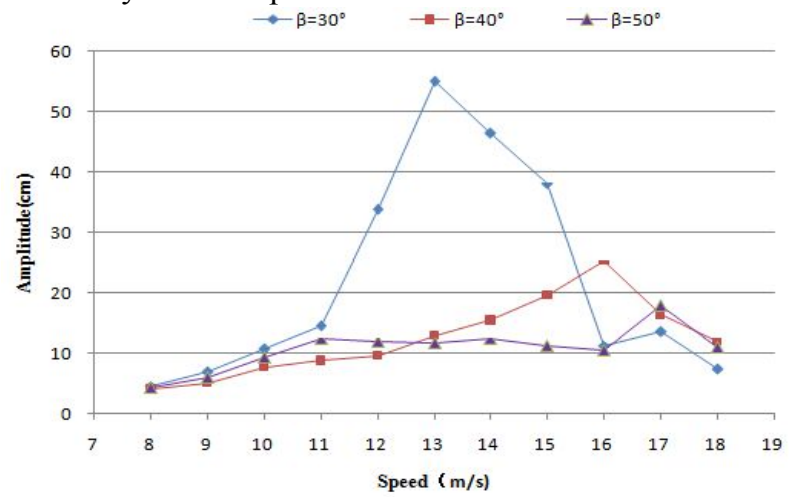

Figure 4. The Amplitude of Wind Direction with Wind Speed

The results of the numerical analysis indicate that when wind direction is $30^{\circ}$, the amplitude achieve the highest $(54.91 \mathrm{~cm})$, while in others directions, the amplitude may decrease to a certain degree. So as to say, when designing a program, it is necessary to make sure about the local climate to avoid the heavy vibration.

\section{CONCLUSION}

The large amplitude of vibration is prone to cable when the wind and rain under the incentive. Numerical calculation shows that the vibration occurs, the rain waterway direction change along with the change of wind speed, the amplitude of the cable first increases with the increase of wind speed, along with the increase of wind speed decreased after. As the change of wind direction, the amplitude of the cable also has the very big change, in the direction of the wind Angle of $30^{\circ}$, the amplitude of the cable is bigger. Rainfall is different, the amplitude of the cable are very different, the greater the rainfall, the greater the amplitude of the cable.

With the increasing of cable-stayed bridge span, the vibration of stay cables is also increasingly apparent, especially rain-wind-induced vibration. The vibration of cables will not be allowed to ignore. The research on the this program is essential and urgent. Also, the resistance measures must be taken into consideration while designing and constructing a cable-stayed bridge. 


\section{References}

1. H. Yamaguchi.1990. "Analytical study on growth mechanism of rain vibration of cables". Engineering and Industrial Aerodynamics 9.73-80.

2. M. Matsumoto . 1995. "Response characteristics of rain-wind vibration of stay-cables of cable- stayed bridges” . Engineering and Aerodynamics 57.323-333.

3. Scanlan R H.1977. "Motion of suspended bridge spans under gusty wind” . ASCE 103.1867 1883.

4. Y . Hikamim, N. Shiraish.1998. "Rain-wind induced vibration of cables in cable stayed bridges” . Journal of wind Engineering and Industrial Aerodynamics 29.409-418.

5. Xiang.H.F Ge.Y.J Refinements on aerodynamic stability analysis of super long-span bridges [J]. Wind. Eng. Ind. Aerodyn 200214931515

6. C. Verwiebe. H. Ruscheweyh. Recent research results concerning the exciting mechanisms of rain-wind - induced vibration, 2EACWE, Italy,1997: 1783-1789 